\title{
The Motion Picture Editors Guild Treatment of the Film Sound Membership: Enforcing Status Quo for Hollywood's Post-Production Sound Craft
}

Labor Studies Journal 2020, Vol. 45(3) 273-295

(C) 2020 UALE

Article reuse guidelines: sagepub.com/journals-permissions DOI: $10.1177 / 0160449 \times 20912337$ journals.sagepub.com/home/lsj

\author{
Stephen Andriano-Moore ${ }^{\prime}$ (i)
}

\begin{abstract}
The Motion Picture Editors Guild (MPEG) is the labor union representing postproduction workers in the Hollywood motion picture industry, including seven sound craft classifications. The sound craft has low status within the hierarchical structure of the Hollywood film industry in comparison to other filmmaking crafts. This article evaluates the workings of the MPEG in concerns with the sound craft and status within the industry through a thirty-plus year review of their professional journal, website, sound practitioner discourse, and other industrial documents. The article argues that the union does not sufficiently protect sound practitioners from employer exploitation, contributes to the alienation of sound practitioners from their work, and constraints the level of and recognition for creative contributions. These actions are seen as perpetuating the low status of sound practitioners and the sound craft, which weakens the power of the union.
\end{abstract}

\section{Keywords}

motion picture, labor union, film sound, Hollywood, production studies, media industries studies, IATSE, MPEG, film production labor, below-the-line

\section{Introduction}

The Motion Picture Editors Guild (MPEG) Local 700 is one of the few national locals of the union that represents below-the-line motion picture workers, the International

\footnotetext{
'University of Nottingham Ningbo China, Ningbo, China

Corresponding Author:

Stephen Andriano-Moore, School of International Communications, University of Nottingham Ningbo China, 199 Taikang East Road, University Park, Ningbo 315100, Zhejiang Province, China.

Email: stephen.andriano-moore@nottingham.edu.cn
} 
Alliance of Theatrical Stage Employees, Moving Picture Technicians, Artists and Allied Crafts of the United States, Its Territories and Canada (IATSE). It has been argued that during, and shortly after, the shift in Hollywood from silent to sound film, the treatment of the sound craft and practitioners by studios, established crafts, and the tumultuous labor organizing of sound workers largely impacted the status of the sound craft and practitioners (Sergi 2017). Sound craft and practitioners were treated as semiskilled and technical rather than creative workers which, as newcomers to the film industry, got in the way of the established filmmaking crafts (Storch 2013). The early history of filmmaking craft unionization, the 1920s and 1930s in Los Angeles, split the sound craft in two groups, weakening their strength as a unified craft and removing sound as a unified part of the filmmaking process (Sergi 2017). By 1930 IATSE Local 695, which initially represented projectionists and camera crews, began to represent on-set production sound practitioners (Smith 2010). Off-set employed sound editors came to be represented by the Motion Picture Film Editors union in 1937, which initially bargained for wages of the newly covered sound editors at 40 percent less than the wages of picture editors (Sergi 2017). As Sergi $(2017,279)$ has claimed, these formative years and decisions of the filmmaking unions contributed to the low status of the sound craft within the hierarchy of production through

(1) the way sound workers were perceived and paid; (2) how production practices were structured, most significantly on-set politics; and (3) the way in which unions contributed to the classification of sound primarily as a post-production, technical process.

The status of a filmmaking craft relates to its position to other crafts within the hierarchies of production. Craft and practitioner status is based on several factors, not limited to, industry acknowledged and perceived levels of technical or creative contribution to a film, extent of collaboration with above-the-line practitioners/crafts, screen credit position, and wages. Higher wages, front and end card screen credits or placement in the crawl, collaboration with the director or producer, and a high level of creative contribution are seen as markers of high status. Currently, many sound craft workers continue to view themselves as working in a low-status craft within the Hollywood film industry. The low status of sound is widely discussed by the Academy Award winning re-recording mixer, sound designer, and supervising sound editor and MPEG member Randy Thom. Thom has stated, "we sound people have been third class citizens in filmmaking for too long" (interview with the author, November 14, 2011). The low status of sound is perhaps most evidently expressed through hiring practices where production sound practitioners are often hired close to the start of the production phase and post-production sound practitioners are often hired in similar fashion either at the start of post-production or after picture editing has begun These hiring practices limit or exclude the participation of sound practitioners from any structural input that largely takes place during pre-production. Such practices influence MPEG members, such as Dave Stone and Randy Thom, to see themselves as viewed by the industry as low in the filmmaking hierarchy (Stone 2008; Thom 2008). 
This article focuses on understanding the union representing post-production sound practitioners, the IATSE Motion Picture Editors Guild Local 700, to illuminate its impact on the occupational culture of Hollywood post-production film sound practitioners and the contemporary status of sound. Specific emphasis is placed on the time period when Local 700 was formed in 1998 and all post-production sound roles merged into this local. In Industrial Approaches to Media, Matthew Freeman $(2016,63)$ stated that media industries research is "partly about understanding relationships between structure (social hierarchies, political forces, economic motives, policies, etc.) and agency (how people create and produce, how teams are forms, how media and audiences are conceptualised, etc.)." This article contextualizes the working practices and culture (practitioner agency) within wider contexts (structures) of union membership and the Hollywood film industry. This article argues that the MPEG perpetuates the low status of film sound that has plagued sound since it was first unionized almost 100 years ago.

This article is informed by the critical perspectives in industrial relations, which views "the employment relationship as an unequal power relation embedded in greater social and political inequalities" (Budd and Bhave 2008, 93). Similarly, critical labor studies concern "thinking about power and exploitation-how we theorise it and might resist it" (Gill 2014, 13), or as Mrozowicki, Stewart, and Zentai $(2015,23)$ states, "critical labor studies is concerned with the purpose of work and what problems it creates for workers." Both concepts contribute to the framing of this study through the lens that views the Hollywood film industry and structures of collective bargaining and labor representation as sites of unequal power relations and exploitation.

The MPEG is examined through the "substantive rules that specify the content of the employment relationship" (wages, hours of work, methods of working, etc.) and "procedural rules that govern interaction and behavior of the parties" (collective bargaining, consultation, information disclosure) through a critical perspective revealing the inequalities and deficiencies in labor representation (Heery et al. 2008, 3). The MPEG will be shown as indicative of the critical model which predicts union management and employers (and above-the-line trade associations) will pursue strategies that increase their control in the workplace and thus control over the employees/union members (Budd and Bhave 2008, 107). Union membership is a contested arena of power and control and is part of a broader societal clash between competing groups (Kelly 1998).

Recent scholarship, Precarious Creativity (Curtin and Sanson 2016) and Voices of Labor (Curtin and Sanson 2017), focuses on labor issues experienced by pre-production and production workers in relation to unions and trade organizations, though none of the research or interviews engage with film sound practitioners. In Precarious Creativity, John Caldwell $(2017,39)$ discusses the concept of "Craft World" which lies within the boundaries of union regulation, trade organization contracts, and craft worker wage labor for studio feature films and quality network TV. This article is in line with Caldwell (2017), as it examines the "Craft World" of post-production film sound practitioners.

There are several theoretical and methodological approaches to illuminate the practices, rituals, and routines of media production practitioners, organizational 
formations, and media industry communities to better understand the culture of the media industry. This article uses theoretical and methodological frameworks from Industrial Approaches to Media (Freeman 2016), which contextualizes previous methodological and theoretical framework discussions into an encompassing account of approaches into micro-level studies of media industries. Freeman (2016) adapts and expands on Havens, Lotz, and Tunic (2009) in their article "Critical Media Industry Studies: A Research Approach," which encourages investigations at the micro-level, such as trade paper and social media analysis, interviews, and ethnography that are examined through macro-level political economy, cultural studies, and social theory frameworks. Similarly, in the edited collection Media Industries: History, Theory, and Method, Holt and Perren $(2009,1)$ state that research into media industries engage with "texts, markets, economies, artistic traditions, business models, cultural policies, technologies, regulations, and creative expression."

Macro-industrial level studies approach issues and areas of ownership, regulatory, institutional, economic, and operational studies with a "top-down" perspective of the media industry (Schatz 2009, 46). Micro-industrial level studies shift focus from the dominance of macro-industrial studies of the industry at large to a more focused perspective on individual companies, distinct market sectors, studios, and divisions (Schatz 2009, 48). Micro-level studies explain "a grounded, empirically based understanding of media industry practices, including the operations, business models, and day-to-day realities of the media industries past and present" (Holt and Perren 2009, 3).

This article utilizes the three industrial contexts for media industries research as proposed by Freeman (2016). The first context is the societal context, "where industrial operations are seen as forming out of deep social structures" (Freeman 2016, 13). The second is the corporate context, "which concerns the working practices that make up production cultures within the media industries" (Freeman 2016, 13). The third is the discursive context, which concerns "the discourses communicated by media industry practitioners, and thus the ways in which media practitioners narrativise the transformation of deep social structures into clear sets of meanings and understandings about the media industries" (Freeman 2016, 13).

Consistent with media industry studies presented above, this article takes an empirically based micro- and macro-level approach to the study of the professional culture of Hollywood film sound practitioners in the area of union membership and representation. Aspects of the Hollywood film industry and labor unionism are discussed at the macro-level scale within the societal context. The micro-level corporate contexts include employment, working practices, and the discursive contexts of practitioner discourse with emphasis on their occupational culture. The professional culture of Hollywood film sound practitioners is illuminated through two main registers: (1) the issues, conditions, and politics of Hollywood film sound labor concerning practitioners and (2) the functions of unions and their interactions with the issues, conditions, and politics of labor. Practitioner labor concerns include screen credit recognition, job titles, work roles, and filmmaking practices. Conditions of labor primarily refer to 
occupational aspects of employment: wages and benefits, hiring practices, and work schedules. Politics of labor concentrate on social and ideological struggles in the workplace, including the effects of industrial structures and hierarchies and the social and ideological relations, negotiations, contestations, and bargaining among and between the filmmaking crafts, practitioners, and their employers. Specific political issues include struggles over professional identities and status, issues of importance, power, influence, and perception. These issues, conditions, and politics of labor are unresolved and are reoccurring topics among Hollywood film sound practitioners and union publications.

The primary empirical evidence for this article is what John Caldwell (2008) calls critical industrial practices. Critical industrial practice refers to self-theorizing critical discourse the media industry and media industry workers produce concerning their work cultures (Caldwell 2008, 202). Critical industrial practices that inform this article are found in numerous sites including union websites and journals, practitioner interviews, and internet forum discussions where film sound practitioners congregate to discuss their work and the impacts on their occupational culture. These sites are examined for what Caldwell calls "industrial reflexivity," which is understood as the self-reflexive discourse from industry professionals used to describe their understanding of their industry, work culture, and themselves (Caldwell 2008, 5). The industrial reflexive practitioner discourses are rich with information about the concerns, activities, and negotiations of practitioners and reveal much about the professional culture of Hollywood film sound.

The critical industrial practices that inform this article are found within what Caldwell calls semi-embedded deep texts and rituals, which circulate within and between industrial groups (Caldwell 2008, 202). Semi-embedded texts travel outside specific work subcultures but within the wider culture and community of film and television workers. These types of self-disclosures project a mediated look at industrial workings that, when critically analyzed, reveal much about the culture that produces them. Critical analysis of the industrially reflexive discourse is conducted in the form of a discourse analysis as presented by Taylor $(2012,7)$ as "the close study of language and language use as evidence of aspects of society and social life."

This case study examines the naturally occurring practitioner discourse of MPEG sound classification members from internet forums they participate in, which include the Yahoo Groups Sound Article List (https://groups.yahoo.com/neo/groups/soundarticle-list/info) and Sound Design List (https://groups.yahoo.com/neo/groups/sound design/info). The other internet forums where sound practitioners congregate are JW Sound (www.jwsoundgroup.net), founded by two-time Oscar nominated production sound mixer Jeff Wexler, and the internet forum for the professional audio website (apologies for the innuendo) gearslutz.com (https://www.gearslutz.com/board/). This article will place these practitioner discussions in dialogue with further discourse analysis of published interviews and articles from the official journal of the MPEG from 1984 through 2020 and the MPEG website from 2009 through 2020. Further resources include documents published by other industrial organizations including above-theline unions and trade associations. 


\section{Trade Associations and Hollywood Unions}

The Alliance of Motion Picture and Television Producers (AMPTP) is the trade association responsible for negotiating the contracts and collective bargaining agreements between film producers and the unions and guilds that represent industry workers. There is a differentiation between the types of unions the AMPTP negotiates with. The Directors Guild of America (DGA), Writers Guild of America (WGA), and the Screen Actors Guild-American Federation of Television and Radio Artists (SAG-AFTRA) are the three above-the-line unions. The below-the-line craft professions are organized into a series of locals and are represented by the IATSE. Above-the-line and belowthe-line distinctions are based on a line drawn on film budgets. Each local has its own specific collective bargaining agreement that productions must abide by as well as the IATSE Basic Agreement. Productions that employ practitioners from the DGA, WGA, and SAG-AFTRA must be signatories of the AMPTP and abide by the collective bargaining agreements with the unions (Ammon 1996, 114). AMPTP signatory productions must hire IATSE unionized below-the-line practitioners including sound editors and re-recording mixers who are members of the MPEG.

The structure of the IATSE includes regional and national mixed craft locals and regional craft-based locals. Currently, there are only two national locals, the MPEG Local 700 and the International Cinematographers Guild Local 800. The MPEG covers all post-production sound professions and other unionized post-production professions, such as studio projectionists, maintenance engineers, cine technicians, music editors, music mixers, and picture editors. ${ }^{1}$ The sound recording membership classifications include re-recording mixer, scoring mixer, and recordist. The editorial classifications are supervising sound editor, sound editor, music editor, and Foley artist. Sound editors select and place sounds on the soundtrack and mixers create the specific qualities, frequencies, tones, and volumes of sound. The MPEG has over eight thousand members, and as the MPEG website states as of January 28, 2020, its collective bargaining agreements cover working conditions, including pay rates, hours and holidays, health and pension benefits, work safety, and artistic (assignment of credit) concerns, though the following will demonstrate the inadequacies of the union's power and capacity, bargaining agreements, policies, and regulations.

\section{Motion Picture Industry Pension and Health Plans (MPIPHP)}

The following examination of the MPEG's recent collective bargaining efforts concerning the members' health care and pension benefits will reveal a diminishing level of power of the MPEG and the IATSE at large. Union power is conceived as their ability to bring about significant effects that further their own interests (Lukes 2005, 65 , cited in Lévesque and Murray 2010,335). This is a form of "power to affect" rather than a form of "power over," which is a form of control. As Lévesque and Murray $(2010,335)$ stated, "this 'power to' refers to the capacity of unions to represents workers' interests, to regulate work and to effect social change." As collective bargaining 
derives from a union's power and capacity, examining the MPEG's collective bargaining concessions of its health and pension benefits is one way to illuminate their diminishing level of union power.

In early 2009, IATSE members voted on whether to pass or not pass the 2009 Memorandum to increase the hours to qualify for and to maintain their health and pension benefits. Sound mixer Jeff Wexler (2009c) posted a message from an anonymous colleague on his Internet forum, JW sound, who stated the increase in hours

will cause something like 3,500 members to be dropped from the health plan. Add to that children, wives, husbands . . . you get maybe 10,000 people who will lose their insurance. The alternative for them, a very expensive COBRA plan, will last for only 18 months. After that, nothing. With pre-existing conditions, doors will slam in their face. How will people who work sitcoms 2 days per week . . camera, sound, hair, makeup . . . ever qualify again? How will people who work day calls on episodic B-Units ever qualify again? How will people who do commercials ever qualify again? This is bad.

The issues were a large concern for the MPEG membership, many of whom took to discussion over social media and other Internet forums (Flood 2010; Grothe 2009; Magaletta 2010; Wexler, 2009a, 2009b).

In spite of negative support, the General Memorandum of Agreement of August 1, 2009, between AMPTP and IATSE was ratified and initiated an increase in the number of hours required for union members to receive health and pension benefits through the MPIPHP (IATSE 2009a). The Memorandum of Agreement affected all of the IATSE locals as it supplemented their Basic Agreement. Previous to August 2009, union members received health and pension benefits if they worked three hundred paid hours per six months. As of August 2009, union members were required to work a minimum of four hundred hours per six-month period (MPIPHP 2007, 32; Repola 2009). In October 2013, the MPIPHP was revised again increasing the requirement for initial qualification and continuance to six hundred union-paid hours of work per six-month period (MPIPHP 2019). In addition, enrolment in the pension plan required a union member to qualify for the health care plan for five consultative years.

In an article on the MPEG special webpage titled "2018 Contract Talk," updated on August 6, 2018, dedicated to the 2019 IATSE Basic Agreement negotiations, states the negotiations "grossly underachieved in the areas of greatest importance," which includes funding the health care and pension plan. According to the MPEG 2018 Contact News webpage, as of August 6, 2018, the DGA and the WGA both negotiated for overseas streaming and new media residuals to fund their health care and pensions, and IATSE failed to negotiate for any income from overseas streaming and new media residuals and failed to earn any new funding streams for their health and pension plan. In 2018, the MPEG was the only Local to vote against ratification, though they were unable to sway any of the other IATSE Locals to vote "No." This action exposed the low power and capacity of the MPEG within the ranks of the IATSE and a diminishing level of the IATSE's negotiation power in comparison to the DGA and WGA. 
Lévesque and Murray $(2010,335)$ theorized that unions can increase their power and work toward renewal by developing and strengthening their resources, which is "at the very heart of the renewal of union power and ultimately entail an ambitious project of self-transformation." An increase in union power at either the IATSE or MPEG level could be pivotal in the upcoming 2021 Basic Agreement as, according to a September 11, 2018 letter to the MPEG membership by the National Executive Director of the MPEG Cathy Repola, the pension plan may become underfunded and will draw funding from the health plan, reducing its coverage. However, the following sections of this article will illuminate the actions and inactions of the MPEG toward the film sound membership and the film sound craft that perpetuate the status quo and undermine the three sources of union power and capacity, which Lévesque and Murray (2010) identified as internal solidarity, narrative resources, and infrastructural resources.

\section{Motion Picture Editors Guild Professional Journal}

The professional journal of the MPEG is the primary communication system for its membership and the Hollywood film industry. Tomm Carroll (2004), the journal editor, calls their journal "the Guild's chief communication tool and its most visible calling card." Union officials, journalists, and members use the official publication to discuss current professional topics and discuss and promote their work. Caldwell $(2008,16)$ stated the professional association publications advance status and recognition by making the aesthetic practices and discourses available to the entire industry "by cultivating an aura of serious scholarship and intellectual inquiry about the 'art' form." Likewise, Hudson and Hudson $(2005,274)$ support the value of official publications that offer insights into the views of the professional association as well as interacting with issues, conditions, and politics of labor.

A union's professional journal is a power resource for framing agendas and serves as a narrative resource, which "refers to the existing stock of stories that frame understandings and union actions and inform a sense of efficacy and legitimacy" (Lévesque and Murray 2010, 336). Lévesque and Murray $(2010,339)$ further state,

Narrative resources consist of the range of values, shared understandings, stories and
ideologies that aggregate identities and interests and translate and inform motives. . .
They are resources because they constitute a body of interpretative and action frames that
can be mobilized to explain new situations and new contexts and point to consecrated
repertories of action.

Narrative resources reflect an organization's values, projects, and repertories of action and sometimes suggest types of pursuits. They are significant as new union members are often socialized into these discourses.

The first contemporary official publication of the MPEG was the Editors Guild Newsletter, which ran from 1979 through January 2000 in its twenty-first volume. The journal was renamed Editors Guild Magazine, which was published from March 2000 
through 2011. In 2011, the journal changed to its current version titled Cinemontage. Cinemontage refers to a style of picture editing called montage and delineates the importance of picture over sound in how the guild presents itself to its membership and the Hollywood film industry.

The examination of the MPEG journals since 1984 has identified a shift in the assortment of articles and topics altering how the union framed itself. Between 1984 and 2011, articles ranging from feature to regular columns discussed issues, politics, and conditions of labor. When the journal was revamped to Cinemontage, it moved away from profound discussions on labor and focused more on discussing the work, job histories, and career paths of its members. The journal shifted away from a critical look at the industry, work roles, and representation to a softer, more uncontroversial, approach. The shift toward articles focusing on members' career paths shows an emphasis on using the journal more as a recruitment tool. The new discourses reveal the changing agenda of the MPEG in response to economic forces outside the union's control, such as precarious working conditions, runaway productions, and a move toward nonunion low-budget television and streaming productions. The new approach also focuses more on articles framed to advancing the status of its members through discussions of members career achievements and their work on particular projects (Caldwell 2008). However, this shift is indicative of what Juravich and Bronfenbrenner (2005, III) discussed as a general shift in union priorities where "larger political questions, as well as the smaller more specific questions about work and workplace struggles, largely disappeared."

Lévesque and Murray $(2010,340)$ stated that new methods of recruitment are seen as a way for enhancing the power resource that they call infrastructural resources, which "refer to material and human resources and to organizational practices, policies and programmes." However, this examination also found that all three iterations of the journal created and reinforced a separation between sound and picture in terms of the elements of a film, as filmmaking crafts, and union membership classifications. Since 1984, there are no feature articles or cover stories that discuss the work of both sound and picture practitioners on a single motion picture. The few times members of both the sound and picture classifications are featured in the same column is in letters to the editor or response letters, rather than commissioned articles. This is significant as it perpetuates differences between, and a separation of, the picture and sound members.

Union collective identities, which "entail a perception of a shared status or relation, either imagined or experienced directly," are important union power resources within the category of internal solidarity (Lévesque and Murray 2010, 337). Internal solidarity relates to union members' collective cohesion and mechanisms developed to ensure such member relations (Lévesque and Murray 2010, 336). The separative acts within the MPEG journal can be seen as weakening union power, as according to Lévesque and Murray (2010, 337), identifiers of a weakened or weakening unionism are "an increased societal emphasis on individualism and differentiation."

The MPEG journal website used to have a back-issue collection dating back to 1984; however, in 2017 the archive was changed to only go back to 2014, a few years after Cinemontage was introduced. The MPEG has essentially erased from 
public records thirty years of significant practitioner interviews and discussions, many of which questioned and illuminated labor issues that were, and still are, significant for its membership. The Editors Guild Magazine and the Editors Guild Newsletter discussed labor issues, whereas Cinemontage generally shies away from controversy. These factors are significant and reveal the perceptions of the guild and how the guild wishes to be represented. As Hadas (in Freeman 2016, 137) has stated, documentation, such as the MPEG's official journal, "represent a permanence in time, as it is documented interactions, accounts and commitments that are kept for posterity and eventually makes up the official history of the media industries." By removing the history of the MPEG's engagement with politics and conditions of labor from the public record, the MPEG added a sense of legitimacy to their shift away from such concerns; as the saying goes, "out of sight, out of mind."

\section{Multiple and Overlapping Work Roles}

There are two forms of multiple work roles in respect to sound editors and re-recording mixers. One form is the Northern California approach to film sound that emerged outside of union regulations and jurisdictions in the San Francisco Bay Area in the 1970 s and 1980s, where a single practitioner was both the re-recording mixer and either the supervising sound editor or sound designer of a film (Andriano-Moore 2018). Gary Rydstrom was both sound designer and re-recording mixer for Cocoon: The Return (1998), and Ben Burtt was both sound designer and re-recording mixer for Star Wars: Episode VI-Return of the Jedi (1983). The Northern California approach to film sound continues to be practiced when the practitioner is hired for the multiple positions and is thus justly compensated.

The second form of multiple and overlapping work is when sound editors are both editing sound and pre-mixing, while being solely hired as a sound editor and paid only sound editing wages. Such work is at times mandated by the employer (Chris Carpenter and Rick Kline in Kalish 1998), and in many cases such work has become normalized into the expectations of employers (Mangini in Kaufman 2010). According to the MPEG's "About” webpage, "the primary job of the IATSE (www.iatse-intl.org) is to negotiate the contracts under which we all work and to protect our safety and well-being from employer exploitation." This remit concerning employer exploitation in terms of its sound editors doing the job of a re-recording mixer has been a concern and a reality for decades. Eventually, the union sided with the employers by establishing a clause regulating such practices. Much of the discussion concerning the multiple and overlapping work role issue of labor has come from MPEG members in the recently removed archive of the first two iterations of the professional journal of the MPEG, though discussions continue on internet forums where sound practitioners congregate.

While some sound practitioners are sought after for their ability work in the capacity of the Northern California approach to film sound, the practice of holding multiple roles in sound is typically not supported in Southern California for several reasons, many of which stem from the early Hollywood studio system. Sound 
practitioners specialized in a single work role, such as editor or mixer, and joined the MPEG based on that single work role. Before digital audio workstations (DAWs) were introduced to post-production sound editing and mixing in the late 1980s, sound editors and re-recording mixers used very different machines. While currently all of the post-production sound work roles are unionized in Local 700, before the major union merger, in November 1998, sound mixers and sound editors belonged to separate unions. The separation of unions restricted multiple sound roles of practitioners in Southern California as opposed to those working in Northern California (Mangini in Kaufman 2010). The previous separation of post-production sound work roles into different unions contributed to what Sergi (2017) called the weakening of the sound craft by restricting it from being a unified part of the filmmaking process.

It is significant that the MPEG's professional journal, in the pre-Cinemontage time period, published five articles delineating the concern of sound editors' multiple and overlapping work roles (Benoit 2005; Hemphill and Massey 1998; Kalish 1998; Kaufman 2010; Kunkes 2006). Starting in 1998, when re-recording mixers merged into the MPEG joining the sound editors, the union brought this labor issue out as a narrative resource, framing themselves as a union both embracing their new member classification and considerate of the conditions of labor. The discussion first took place within the Motion Picture Editors Guild Newsletter in the article "Overlapping Jobs and Monster Soundtracks: An Interview with Mixers Doug Hemphill and Paul Massey" (Hemphill and Massey 1998) and in the article titled "Sound Mixing: Two Teams of Mixers on a Mix of Topics" (Kalish 1998).

The article "Overlapping Jobs and Monster Soundtracks" opens with Hemphill commenting on the merger that brought all unionized post-production sound professions under one Guild. Hemphill (Hemphill and Massey 1998) answers,

Well, it's something we've been seeing coming down the road because of the way our jobs are overlapping more and more, where editors are starting to bring in elements that are more finely tuned-I don't want to say pre-mixes but material that has clearly been designed and put together out of a lot of different elements.

Academy Award mixers Chris Carpenter and Rick Kline (in Kalish 1998) state they view merging work roles in similar ways to Hemphill in stating,

This is a result of the work being interchangeable with workstations. The roles used to be very clear and defined; who cut, who actually did manipulations of one kind or another. Now, with the sophistication of equipment, many independent sound editorial houses (and sound editors) are doing their own combining of pre-mixes . . by the time it gets to the stage, it has actually been worked on.

The two articles reveal how directly after the merger the professional journal and the union was interested in discussing important issues of labor concerning working practices. These were the first public discussions circulating among the union from the newly acquired re-recording mixers, who were making compelling cases that the work 
roles of sound editors and mixers were facing significant changes in the workplace. However, the union missed the opportunity at the time of the merger to act upon these issues of labor and protect re-recording mixers from the encroachment of sound editors into their areas of work and to protect sound editors from exploitation.

While these issues have come under scrutiny within articles on different topics (Benoit 2005; Kunkes 2009a), the issues became a featured article in the Editors Guild Magazine in "Sound Clash: It's Mixers vs. Editors as Audio Post Budgets Fade" (Kaufman 2010). Whereas in the first narratives concerning multiple overlapping work roles was framed within a discourse of technological innovation (Hemphill and Massey 1998; Kalish 1998), ten years later, the same issue was framed within the discourse of shrinking audio post-production budgets (Kaufman 2010). Both framings place the cause of these labor practices on economic industrial forces that are outside union control, which the union was unable to adequately protect their membership from.

Former sound supervisor, ADR mixer, and recordist Ann Hadsell (in Kaufman 2010) stated, "while the overall film budgets are increasing, there is a trend that postproduction budgets are shrinking." Practitioners such as Massey (in Kaufman 2010) claim less time and money are allocated for post-production sound, the film soundtracks are 200 to 300 percent more complex than those in the 1990s, and often post-production practitioners work overtime for six or seven days a week (Hemphill and Massey 1998). In many cases where sound editors were under budgetary and time demands, they often were "pressured to create temp-mixes or pre-mixes in order to cut down time spent on the dub stage," where the mixers work (Kaufman 2010). According to Mangini (in Kaufman 2010),

Clients are now mandating that the same amount of time in editorial should include mixing in the box [the editing suite]. You have an art vs. commerce conundrum. If you're working more hours to get the mixing done because you have pride in your work, and you're not compensated for those hours, that's a problem that needs to be investigated.

The more practitioners are put to work in underpaid and impacted schedules, the more it becomes expected and naturalized within the industry. As Minkler (in Kaufman 2010) says, "this misrepresentation is allowing budgets to be slashed and corrupting what quality sound should be." While not all productions that have editors mix are sacrificing quality, Minkler (in Kaufman 2010) warns,

However, too often, sound professionals are being used and abused by ignorant, greedy and/or careless employers to multitask for extremely long hours using inappropriate technology without proper compensation.

Minkler's sentiments about inappropriate technology refer to mixing at editing stations where the monitors and acoustics differ greatly from a mixing stage. As there are multiple sound editors on a production, this workflow can result in a mix containing "different styles and perspectives" (Millan in Kaufman 2010). However, the digitization of these mixes makes it so any pre-mixing "can be undone if necessary" (Schatz in Kaufman 2010). 
The MPEG brought the issue of multiple and overlapping work roles between its long-standing members, the sound editors and its newly acquired re-recording mixers, into its union and industry-wide discourse from the late 1990s through the end of the 2000s. These articles framed the union as sympathetic to the unjust working conditions of sound editors and the potential impacts such work had on re-recording mixers. However, none of the articles engaged deeply into a critically important issue, that of wages and qualifying hours for the health and pension plan.

Eventually, the MPEG dealt with the issue of practitioners working outside their classification; however, the regulations favored the employer rather than the employee. The 2009 MPEG Post Production (Majors) Agreement, Section 12 Interchange of Job Classification states (MPEG 2009, 43) as follows:

The parties recognize that new technologies allow for multiple tasks and functions to be performed by one individual at a workstation. Employees will be engaged in a particular classification based upon the primary skill required. Employees may perform tasks in any other post-production job classification(s) which tasks are secondary to their primary duties.

These actions legitimized and legalized the practice of hiring sound editors to work up to half of their employed time on other duties such as building pre-mixes and providing employers the ability to have reels premixed by sound editors at their DAWs at a wage rate far less than mixers.

According to the 2018 IATSE Post Production (Majors) Agreement on the Motion Pictures Editors Guild's website, Sound Editors (category Z-5cc) have a weekly rate of $\$ 2,537.89$ and an hourly rate of $\$ 52.22$ and the weekly rate for re-recording mixers (Y-1) is $\$ 3,197.88$ with an hourly rate of $\$ 65.80$. Due to the wage differences between a Z-5cc editor and a Y-1 mixer, studios save nearly 35 percent per hour in wages for mixing when editors pre-mix in comparison to a mixer. As such, editors tasked with mixing are working those hours for 35 percent less than they should be compensated for. This also takes away hours from mixers, and thus lowers their wage intake for a given job. The other impact from editors pre-mixing is the loss in the number of worked hours for mixers to qualify for, or maintain, health and pension benefits. Editors conducting part of the mix have further implications in terms of alienation. Editors are working without credit for their artistic contribution to the mix. Mixers have reduced artistic contribution as they are being presented with pre-mixed reels.

The discussion has highlighted "the changing nature of work and its impact on workers" and the union's response (Juravich and Bronfenbrenner 2005, iii). The technological and economic changes within the Hollywood film industry brought out an easily exploitable labor practice that has led to what Gill $(2014,13)$ calls an "intensification and extensification of work." While the MPEG removed discussions that were against their membership working outside their job classification from their archive, the MPEG agreed to support this practice by ratifying the policy into the Basic Agreement. As Lévesque and Murray $(2010,334)$ have stated, "the declining influence of unions is often equated with their diminished capacity to protect and improve the working conditions of their members and with decreased influence on economic and social policies 
that benefit workers." In this case, the MPEG has not protected its sound editors from exploitation and alienation of their work, but has supported such practices, which is indicative of the declining power of unions (Fairbrother et al. 2007).

\section{Sound Designer Job Title}

The sound designer job title is a contentious title, and several issues and politics of labor are intertwined within. It is a job title and screen credit widely used by MPEG sound editors, though not officially recognized by the MPEG. Sound designer and MPEG member Ben Burtt (in Kunkes 2009b) stated, "there is no single accepted job description for sound designer." The job title of sound designer for motion picture production originated in the late 1960s in Northern California. It was developed to assign credit to a new role for sound practitioners working as a department head for sound where a single person is in charge of the overall creative vision for the use of sound and works throughout all the stages of filmmaking (Andriano-Moore 2018, 548). As sound designer became a popularized screen credit, it was adopted throughout the industry to denote a "person who designs interesting, unique sounds," or a fabricator of sound effects (Murch in Jarrett 1999). Hollywood practitioners working in either conception of the job title are registered with the MPEG as sound editors (Jennings 2010).

While many of the filmmaking crafts such as cinematography and production design have department heads that work with the director starting at the pre-production phase, it is extremely rare for a director to work with a department head for sound during pre-production. Production sound practitioners are often hired close to the start of the production phase and post-production sound practitioners are often hired in similar fashion either at the start of post-production or even later after picture editing has already begun. Traditionally, the supervising sound editor can fulfill the role of a department head for sound, though often only during postproduction. These hiring practices limit the participation of sound practitioners from any structural input on a film, which is primarily conceived in the pre-production phase.

The hiring practices are symptomatic of the perceived low status of film sound where most producers and directors do not see a need to work with any sound practitioners during the pre-production stage. This regulates sound work to only be attached to a structure that is already in place where only the picture can help shape the sound, but sound has a limited ability to shape the picture (Thom 1998). It is also indicative of the separation of the production and post-production sound crafts into different Locals, and thus little collaborative work between the two. These conditions have inhibited the use of a sound designer in the original sense on the majority of contemporary Hollywood film productions. Thus, the sound craft is treated with a lower status in the hierarchy of filmmaking crafts than those crafts that are part of the pre-production phase such as camera, costume, or the art department, those that contribute to the structure of a film. 
MPEG definitions and duties of job classifications reveal drastically different work roles for the department head for picture editing (Z-1 Motion Picture Editor) and for the official department head for sound (Z-4 Supervising Sound Editor). The definitions and descriptions are as follows (MPEG 2009, 114-115):

"Z-1 Motion Picture Editor" shall be deemed to mean a person actually engaged in the editing of motion pictures into proper sequence and story form. Editors shall, whenever requested by the Producer, advise the Producer in a creative and technical capacity with reference to any optical effects, special visual effects, stock footage, re-shoots and insert materials. . . In order to perform satisfactorily the above job functions, it is recognized that Editors should be given every opportunity to view dailies and attend dubbing sessions.

"Z-4 Supervising Sound Editor" shall be deemed to mean a person engaged in the supervision of groups of Sound Editors engaged in the making or creating of sound or sound effects and/or the creating or making of such sound or sound effects and/or engaged in assembling and synchronizing sound or sound effects tracks.

The Z-1 classification provides for the head editor to work with the producer and director during the production phase when the film is being shot. The Z-1 classification identifies this person as working in a "creative capacity," which is not part of the Z-4 job description. Picture editors are seen as creative contributors, while the supervising sound editor is not identified as the film's creative contributor, labeling film sound practitioners as technical rather than creative or artistic workers. No sound classifications have creative capacities as part of the job description. Many sound editors, such as David Farmer, Scott Gershin, and Lance Brown, state they use the job title of Supervising Sound Editor when working either as the sound designer in the original conception or as the supervising sound editor as defined by the MPEG, because for either position they are contracted and paid as a supervising sound editor (Brown 2000; Farmer 2000).

Randy Thom (2010) chooses to use the job title and screen credit "supervising sound designer" when working in the capacity of a sound designer as it was originally conceived to more accurately identify his contributions to a film. Using the credit of supervising sound designer is an attempt to raise the status of film sound as it allows others to have a greater sense of a creative undertaking since the Z-4 position is classified as supervision of people rather than supervision over the use of sound. When working in the capacity of the appropriated use of the job title sound designer, some practitioners, such as Harry Cohen, use the credit Sound Effects Designer (Cohen 2000). The advent of the sound designer role and screen credit has led to over half a century of MPEG member sound editors using various unofficial screen credits to provide a name for recognition of the work they conducted on a particular film as the official MPEG classifications are deemed inadequate. 
In 2008, the MPEG "What Our Members Do?" webpage described sound designs and sound editors as conducting the same work. ${ }^{2}$ The "What Our Members Do?" section in the MPEG (2008) website stated,

Once picture has been finalized (or "locked"), more creative individuals bring their contributions to bear. Sound Designers and Sound Editors build the audio tracks to create full sonic worlds and create a deeper sense of believability. (emphasis in original)

The above statement reveals that the IATSE and MPEG do not draw deep distinctions between sound design and sound editing and have removed the context of its original conception as department head for sound throughout the entire filmmaking process. The description states that sound designers begin work only at the start of the post-production phase after the picture editing is completed. Through these discursive acts, the union representing the sound practitioners has denied the sound craft and the practitioners' recognition for their work that has the potential to raise the status of sound within the industry. However, when film sound practitioners are introduced and discussed within the MPEG website and even in Cinemontage, many sound practitioners are distinguished as a sound designer (Carroll 2017, 5; Kaufman 2017, 34-39; Lambert 2014, 39-44; Lambert 2019, 50-55). The way the MPEG uses the job title is contradictory as it is not an official job title or membership classification, but it is widely used through the industry and throughout the MPEG.

There has been a long-standing opportunity for the MPEG to define and classify the traditional work role of the sound designer and create a new MPEG classification to establish a new tradition of a department head for sound that both supervises sound practitioners as a Z-4 supervising sound editor does, but also collaborates with the director and other department heads during pre-production to consult the ways in which a film can be produced to incorporate sound more integrally into the storytelling process. Such a step would raise the status of sound within the film industry and would provide a more specific work role that some sound editors and supervising sound editors currently practice. This would also strengthen the union through empowering and strengthening the identity of its membership and their importance in the filmmaking process.

\section{Screen Credits}

Unions stratify hierarchies through screen credit regulations, an issue stemming from the DGA's control over many screen credit regulations. Above-the-line guilds such as the DGA, WGA, and SAG-AFTRA have stronger clout than the IATSE and its Locals in terms of regulations and campaigns over screen credits. The above-the-line guilds' stronger influence reinforces hierarchies and the division of labor when they prevent below-the-line professionals from receiving front card screen credits. While the IATSE and the MPEG state they protect their members' assignment of credit, their members reveal the level of protection is minimal. 
Union-negotiated collective bargaining agreements, industry traditions, and in some cases personal contracts mandate provisions for a practitioner's screen credits. Screen credits represent official recognition for work completed on a film and hold inherent value within the entertainment industry. A screen credit is a requirement for consideration for Academy Awards, BAFTA award, and many others. ${ }^{3}$ Screen credits are also needed to join honorary societies like the Cinema Audio Society as well as unions. The size and placement of a screen credit plays a significant role in future fee negotiations and credits in the next project as placement conveys status within the industry (Davenport 1989, 148). ${ }^{4}$ Screen credits also aid in promoting a film. As screen credits hold these inherent values, they are highly important to practitioners. The DGA has the highest authority of screen credits, and as the DGA and the AMPTP consider directing as the highest status craft, their rules affect many crafts in the film industry.

Motion picture screen credits include both the main title and the end credits. Screen credits are either in the form of a "card," which are stationary and are shown at the beginning of a film and sometimes at the end. End credits scroll up the screen in a continuous list of names and titles from the bottom to the top of the screen in what is referred to as "the crawl." Unions, individual contracts, studio policies, film producers and established conventions regulate the size, placement, and form of all screen credits. Films that are produced without a DGA signatory agreement have more flexibility with the main title screen credits as they are not required to abide by DGA screen credit guidelines. The position and size of title credits are highly regulated because of the inherent value and creative recognition they represent. It is generally accepted that the order and size of credits reflect the importance of an individual to a particular film and within the industry. The hierarchy of screen credits is interpreted as such by industry professionals, the guilds and unions, professional organizations, and film audiences. ${ }^{5}$ Highlighting the hierarchical division of labor in film associated with screen credits, former production coordinator, whose responsibilities include assembling the first draft of screen credits on a production, Eve Honthaner $(2010,469)$ states, screen credits other than those mandated by contracts, unions, or guilds are placed in "an underwritten industry-accepted pecking order."

The "pecking order" was created by a perceived industrial status and stipulations in the various Union and Guild agreements with the AMPTP. The MPEG Majors Production Agreement 2009 has four rules for crediting the picture editor in similar terms to those the DGA has for the director, such as the single card credit and the order in which it is placed. However, all credits for sound work are at the discretion of the producer (IATSE 2009b, 110). There are no requirements that sound practitioners receive a screen credit and particular stipulations on credit titles and placements for the post-production sound professions are negotiated within individual contracts with consent of the producer (Honthaner 2010, 470; MPEG 2009, 112-113).

The DGA's regulations regarding screen credits date back to 1939. Today the DGA and the AMPTP have a collectively bargained Basic Agreement stating the DGA's screen credit regulations. Article 8 of the DGA Basic Agreement 2014 has twentyseven sections covering rules regarding screen credits ranging from controversy over credits to forms of credits, visibility of names, rules for advertisements, and even 
pseudonyms (DGA 2014). A DGA signatory production must adhere to these conditions.

The DGA and WGA have dedicated credit departments, while the IATSE does not. Information on DGA and WGA screen credit policies are posted on their websites, while the IATSE and MPEG websites only mention their union protects the members' "artistic concerns (assignment of credit)." There is a strong belief within the IATSE and MPEG membership that the union does very little in terms of protecting their assignment of screen credits. On his forum www.jwsound.net, production sound mixer Jeff Wexler (2010) stated,

Regarding screen credit for sound, this is definitely up to the discretion of the producer. Unless you have a personal contract (rare for sound people) that stipulates screen credit, there is no requirement for any credit to be given to sound people. We have had many discussions over the years with our Union (the I.A.T.S.E.) about this but nothing has ever been done about it. I seriously doubt anything could be accomplished at the Local.

According to MPEG member sound effects editor Pascal Garneau (2008), who is an MPSE Golden Reel Award Nominee for Best Sound Editing for Transformers (2007) and Indiana Jones and the Kingdom of the Crystal Skull (2008), "the furthest IATSE has gone to address this issue is an editorial in their magazine from a few years ago which was in support of an open letter written by the ACE [American Cinema Editors]." Sound practitioners, such as Wexler, have tried to change IATSE union regulations for the protection of recognition in the form of screen credits for sound practitioner to no avail. Screen credit recognition is highly important for film workers, and the MPEG does not have much influential power in the matter.

The editorial "Op-Edit: Giving Credits Where They're Due" in the Editors Guild Magazine does discuss credit issues for its picture editor members but does not address any issues for sound practitioners (Casey and Covington 2005). In reply to a Gearslutz forum thread titled "Sound Credits or 'Is the Caterer More Important than the Sound Department?" Charles Maynes (2008) stated for sound, "the credit thing is so complex ... For me, the \#1 priority is the cheque issued by the accountant (who got higher billing than I did) clearing the bank." The Editors Guild Magazine, however, did state the placement of credits "absolutely affects respect, pay, and status within the industry. For those who think credit placement in the crawl doesn't matter, we're here to say-it matters!" (Casey and Covington 2005). The MPEG assistant editors' representatives (Casey and Covington 2005) also state that "prestige is associated with the placement in the crawl and we want to stand up for the assistants who work so hard." However, the members in the sound profession do not see the MPEG standing up for them to provide regulations for their screen credits.

While the above-the-line guilds place much emphasis on regulating screen credits for their members, the MPEG only provides screen credit protection for their picture editors. Size and placement in front or end cards and in the crawl are important indicators of status and are often perceived as levels of creative contributions to a film. By only regulating picture editor screen credits, the MPEG is reinforcing the perceived 
low status of the sound craft and sound practitioners. Sound practitioners must then work to include their screen credit in their individual contract with no protection from their union, ultimately leaving the size and placement of their screen credit up to the producer.

\section{Conclusion}

This article illuminates the contemporary workings of the MPEG and its interactions with issues and politics of labor in the occupational worlds of Hollywood film sound practitioners. The discussions have demonstrated how the MPEG is perpetuating the low status of the sound craft and of sound practitioners through its alienating labor policies, perpetuation of member divisions, and their low power and capacity for successful collective bargaining and member protection. Their failure to keep up with emerging and long-sustained production practices of the job title sound designer is one of its many missed chances to advance the status of film sound and its sound membership.

The MPEG has treated its sound membership in problematic ways since they became represented by the union. This article has shown that the MPEG will most likely "remain a prisoner of its own history, caught in a path dependency of its repertories and identities: it is likely to follow a trajectory that will not challenge its projects, values and traditions" (Lévesque and Murray 2010, 334). Unfortunately, the MPEG is not learning from, nor listening to, its sound memberships' decades-long discussions concerning more accurate and officially recognized job titles and protections for working outside one's job classification. While the MPEG is perpetuating the lower status of sound craft, it is at the same time shooting itself in the foot, so to speak, by not empowering and strengthening their membership in order to increase their power resources for strengthening the union.

\section{Declaration of Conflicting Interests}

The author(s) declared no potential conflicts of interest with respect to the research, authorship, and/or publication of this article.

\section{Funding}

The author(s) received no financial support for the research, authorship, and/or publication of this article.

\section{ORCID iD}

Stephen Andriano-Moore iD https://orcid.org/0000-0001-9686-6578

\section{Notes}

1. Digital visual effects (CGI/VFX) is considered a post-production craft but it is not currently unionized, though the Animation Guild IATSE 829 is working on unionizing CGI/ VFX. For more information, see Curtin and Vanderhoef (2015) and Curtin and Sanson (2017, chap. 25 and 26). 
2. The website has been revamped several times since, and these descriptions were removed in 2012.

3. An Official Screen Credits (OSC) form is required for an Academy Award nomination.

4. In the 1983 judicial case Smithers v. Metro-Goldwyn-Mayer Studios, the courts deemed that screen credits do hold monetary value and is as important as monetary compensation as they are used in future wage negotiations.

5. Such claims of interpretation are made by the fact that screen credits are highly regulated and screen credit disputes have been decided in the U.S. judicial system.

\section{References}

Ammon, John. 1996. "The Transformation of Industrial Relations in the Motion Picture and Television Industries: Craft and Production.” In Under the Stars: Essays on Labor Relations in Arts and Entertainment, edited by Louis S. Grey, and Ronald L. Seeber, 113-155. New York: Cornell University Press.

Andriano-Moore, Stephen. 2018. "The Rise of the Sound Designer: Northern California Film Sound in the 1960s and 1970s." Historical Journal of Film, Radio and Television 38 (3): 536-54. doi:10.1080/01439685.2017.1357256.

Benoit, Sharon. 2005. 'Last Year's Winners Discuss Their Work. Industry Trends and Their Favorite Films of 2004.” Editors Guild Magazine, January/February 26. no. 1.

Brown, Lance. 2000. "Re: [sound_design] Editor Vs Sounddesigner." Sound Design List. December 23, 11:52 p.m. http://groups.yahoo.com/group/sound_design/message/668.

Budd, John W., and Decasheesh Bhave. 2008. "Values, Ideologies, and Frames of Reference in Industrial Relations." In The SAGE Handbook of Industrial Relations, edited by Paul Blyton, Nicolas Bacon, Jack Fiorito, and Edmund Heery, 92-112. London: Sage.

Caldwell, John. 2008. Production Culture: Industrial Reflexivity and Critical Practice in Film and Television. Durham: Duke University Press.

Caldwell, John. 2017. "Spec World, Craft World, Brand World." In Precarious Creativity: Global Media, Local Labor, edited by Michael Curtin, and Kevin Sanson, 33-48. Oakland: University of California Press.

Carroll, Tomm. 2004. “Editor's Note.” Editors Guild Magazine, November/December 25. no. 6 .

Carroll, Tomm. 2017. "Post Script: Out of Boundaries." CineMontage 6 (3), 5.

Casey, Stephanie M., and Paul Covington. 2005. "Op-Edit: Giving Credits Where They're Due.” Editors Guild Magazine, March/April 26. no. 2.

Cocoon: The Return. 1988. "Director David Petrie.” Century City: Zanuck/Brown Productions, 20th Century Fox.

Cohen, Harry. 2000. "Re: [sound_design] Editor Vs Sounddesigner." Sound Design List. December 28, 10:29 p.m. http://groups.yahoo.com/group/sound_design/message/675.

Curtin, Michael, and Kevin Sanson, eds. 2017. Voices of Labor: Creativity, Craft, and Conflict in Global Hollywood. Oakland: University of California Press.

Curtin, Michael, and Kevin Sanson, eds. 2016. Precarious Creativity: Global Media, Local Labor. Oakland: University of California Press.

Curtin, Michael, and John Vanderhoef. 2015. "A Vanishing Piece of the Pi: The Globalization of Visual Effects Labor." Television \& New Media 16 (3): 219-39. doi:10.1177 $\% 2 F 1527476414524285$.

Davenport, Robert. 1989. "Screen Credit in the Entertainment Industry." Loyola Entertainment Law Journal 10 (2): 129-94. http://digitalcommons.lmu.edu/elr/vol10/iss1/2. 
Directors Guild of America. 2014. "Basic Agreement of 2014. Article 8: Directors' Credits." https://www.dga.org/-/media/E98E71412E1F4BB5B94AE0843C5CD8DE.pdf.

Fairbrother, Peter, Glynne Williams, Ruth Barton, Enrico Gibellieri, and Andrea Tropeoli. 2007. "Unions Facing the Future: Questions and Possibilities." Labor Studies Journal 1 (4): 31-53. doi:10.1177\%2F0160449X0703100404.

Farmer, David. 2000. "Re: [sound_design] Editor Vs Sounddesigner." Sound Design List. December 22, 3:13 p.m. http://groups.yahoo.com/group/sound_design/message/660.

Flood, Brian. 2010. "Joining MPEG as a Sound Editor-Help!” Gearslutz. July 26, 5:06 p.m. http://www.gearslutz.com/board/post-production-forum/513850-joining-mpeg-soundeditor-help.html.

Freeman, Matthew. 2016. Industrial Approaches to Media: A Methodological Gateway to Industry Studies. London: Palgrave Macmillan.

Garneau, Pascal. 2008. "Sound Credits or 'Is the Caterer More Important Than the Sound Department?.'” Gearslutz. June 29, 7:21 a.m. http:/www.gearslutz.com/board/post-productionforum/228681-sound-credits-caterer-more-important-than-sound-department.html.

Gill, Rosalind. 2014. "Academics, Cultural Workers and Critical Labour Studies." Journal of Cultural Economy 7 (1): 12-30. doi:10.1080/17530350.2013.861763.

Grothe, Steven. 2009. "The Affects of the 400 Hour Rule.” Jwsoundgroup.net. March 2, 2:31 a.m. http://jwsoundgroup.net/index.php?/topic/3038-the-affects-of-the-400-hour-rule/.

Havens, Timothy, Amanda D. Lotz, and Serra Tinic. 2009. "Critical Media Industry Studies: A Research Approach.” Communication, Culture \& Critique 2 (2): 234-53. doi:10.1111/ j.1753-9137.2009.01037.x.

Heery, Edmund, Nicolas Bacon, Paul Blyton, and Jack Fiorito. 2008. "Introduction: The Field of Industrial Relations." In The SAGE Handbook of Industrial Relations, edited by Paul Blyton, Nicolas Bacon, Jack Fiorito, and Edmund Heery, 1-32. London: Sage.

Hemphill, Doug, and Paul Massey. 1998. "Overlapping Jobs and Monster Soundtracks: An Interview with Mixers Doug Hemphill and Paul Massey." Motion Picture Editors Guild Newsletter, January/February 19. no. 1.

Holt, Jennifer, and Alisa Perren, eds. 2009. Media Industries: History, Theory, and Method. Malden: Wiley-Blackwell.

Honthaner, Eve L. 2010. The Complete Film Production Handbook. 4th ed. Oxford: Focal Press.

Hudson, James R., and Patricia A. Hudson. 2005. "Associations and Their Journals: The Search for an 'Official' Voice." Sociological Perspectives 48 (2): 271-89. doi:10.1525\%2 Fsop.2005.48.2.271.

Indiana Jones and the Kingdom of the Crystal Skull. 2008. Director Steven Spielberg. Hollywood, CA: Paramount Pictures.

International Alliance of Theatrical Stage Employees. 2009a. "General Memorandum of Agreement of August 1, 2009."

International Alliance of Theatrical Stage Employees. 2009b. "Post-production Agreement of August 1, 2009 between Producer (Majors) and IATSE." https://www.editorsguild.com/ Wages-and-Contracts.

Jarrett, Michael. 1999. "Sound Doctrine: An Interview with Walter Murch.” https://www2. yk.psu.edu/ jmj3/murchfq.htm.

Jennings, Jay. 2010. "How Important Is Union Membership for Sound Designers and Production Sound Mixers?" Social Sound Design. May 4, 11:24 p.m.

Juravich, T., and Kate Bronfenbrenner. 2005. "Introduction: Bringing the Study of Work Back to Labor Studies.” Labor Studies Journal 30 (1): i-vii. doi:10.1177\%2F0160449X0503000101. 
Kalish, Karen. 1998. "Sound Mixing: Two Teams of Mixers on a Mix of Topics." Motion Picture Editors Guild Newsletter, July/August 19. no. 4.

Kaufman, Deborah. 2010. "Sound Clash: It's Mixers vs. Editors as Audio Post Budgets Fade." Editors Guild Magazine, November/December 31. no. 6.

Kaufman, Deborah. 2017. “'Battle of the Sexes': Ai-Ling Lee and Mildred Iatrou." CineMontage 6 (3), 34-39.

Kelly, John. 1998. Rethinking Industrial Relations: Mobilization, Collectivism and Long Waves. London: Routledge.

Kunkes, Michael. 2006. "The Sound of the Future: Warner Bros. Cues Up New Audio Post Facility." Editors Guild Magazine, January/February 27. no. 1.

Kunkes, Michael. 2009a. "Achievement in Sound Editing: Richard King The Dark Knight." Editors Guild Magazine, May/June 30. no. 3.

Kunkes, Michael. 2009b. "Sound Trek: The Audio Explorations of Ben Burtt." Editors Guild Magazine, May/June 30. no. 3.

Lambert, Mel. 2014. "Plugged-In for Sound: Recommended DAW Add-Ons for Designers and Editors." CineMontage 3 (3), 39-44.

Lambert, Mel. 2019. "Witch Doctors: 'Sabrina's' Sound Crew Casts Spell." CineMontage 8 (1), 50-55.

Lévesque, C., and G. Murray. 2010. "Understanding Union Power: Resources and Capabilities for Renewing Union Capacity." Transfer: European Review of Labour and Research 16 (3): 333-50. doi:10.1177/1024258910373867.

Magaletta, Tony. 2010. "Say No To 400 Hours!” Facebook Group. November 9. http://www. facebook.com/group.php?gid=39255782485\&v=app_2373072738.

Maynes, Charles. 2008. "Sound Credits or "Is the Caterer More Important Than the Sound Department?." Gearslutz. July 3, 11:23 p.m. http://www.gearslutz.com/board/post-production-forum/228681-sound-credits-caterer-more-important-than-sound-department.html.

Motion Picture Editors Guild. 2008. "What Our Members Do?" February 5.

Motion Picture Editors Guild. 2009. "Post-Production Agreement of August 1, 2009 between Producer (Majors) and International Alliance of Theatrical Stage Employees and Moving Picture Technicians, Artists and Allied Crafts of the United States and Canada and Motion Picture Editors Guild, Local \#700" August 1.

Motion Picture Industry Pension and Health Plans. 2007. “Active MPI Health Plan.” July. http:// www.mpiphp.org/benefits/active_plan/MP_07_SPD_Active.pdf.

Motion Picture Industry Pension and Health Plans. 2019. “Active MPI Health Plan.” May. https://www.mpiphp.org/home/eligibility.

Mrozowicki, Adam, Paul Stewart, and Violetta Zentai. 2015. "Critical Labour Studies in Hungary, Poland and the UK: Between Crisis and Revitalisation." Forum Socjologiczne 1: 19-34.

Repola, Cathy. 2009. "Contractual Obligations: Every Hour is Worth More Than Ever.” Editors Guild Magazine, July/August 30, no. 4.

Schatz, Thomas. 2009. "Film Industry Studies and Hollywood History." In Media Industries: History, Theory, and Method, edited by Jennifer Holt, and Alisa Perren, 45-56. Malden: Wiley-Blackwell.

Sergi, Gianluca. 2017. "Sound Standings: A Brief History of the Impact of Labor and Professional Representation on the Place of Early Sound Workers in the Industry (19271937)." In The Routledge Companion to Screen Music and Sound, edited by Miguel Mera, Ronald Sadoff, and Ben Winters, 270-280. Oxon: Routledge. 
Smith, Scott D. 2010. "Beginnings of Local 695." 695 Quarterly 2 (4), 16-28.

Star Wars: Episode VI-Return of the Jedi. 1983. Directed by Richard Marquand. San Rafael, CA: Lucasfilm.

Stone, Dave. 2008. "Re: Following the Production Designer's Model." Sound Article List. May 2, 8:47 a.m. http://groups.yahoo.com/group/sound-article-list/message/4136.

Storch, Randi. 2013. Working Hard for the American Dream: Workers and Their Unions, World War I to the Present. Chichester, West Sussex: John Wiley \& Sons.

Taylor, Stephanie. 2012. What Is Discourse Analysis? London: Bloomsbury.

Thom, Randy. 1998. "Designing a Movie for Sound." Motion Picture Editors Guild Newsletter, May/June 19. no. 3.

Thom, Randy. 2008. "Re: Following the Production Designer's Model.” Sound Article List. May 3, 7:51 a.m. http://groups.yahoo.com/group/sound-article-list/message/4138.

Thom, Randy. 2010. "Re: Emotional, Larger Than Life, Stranger Than Life Perhaps, But Believable.” Sound Design List. June 17, 4:11 a.m. http://groups.yahoo.com/group/sound design/message/23989.

Transformers. 2007. Directed by Michael Bay. Universal City, CA: DreamWorks.

Wexler, Jeff. 2009a. "New IATSE Contract.” Jwsoundgroup.net. February 27, 2:38 p.m. http:// jwsoundgroup.net/index.php?/topic/3023-new-iatse-contract/.

Wexler, Jeff. 2009b. "Say NO to 400 Hours Requirement.” Jwsoundgroup.net. January 12, 7:40 a.m. http://jwsoundgroup.net/index.php?/topic/2798-say-no-to-400-hours-requirement/.

Wexler, Jeff. 2009c. "Voting No on the Contract." Jwsoundgroup.net. February 5, 2:24 p.m. http://jwsoundgroup.net/index.php?/topic/2908-voting-no-on-the-contract/.

Wexler, Jeff. 2010. "Re: Screen Credits.” Jwsoundgroup.net. March 7, 8:43 a.m. http://jwsoundgroup.net/index.php?/topic/4695-screen-credits/.

\section{Author Biography}

Stephen Andriano-Moore teaches media and cultural studies in the School of International Communications at the University of Nottingham Ningbo China. His research explores production cultures in the film and television industries with particular focus in the area of Hollywood film sound. 